\title{
Deterioração nos materiais da tubeira de motor-teste em ensaio de queima estática
}

\author{
Degradation in the nozzle materials of subscale motor in a static firing test
}

Deterioración en los materiales de la boquilla de motor-prueba en ensayo de quema estática

\author{
Ronald Izidoro Reis, Doutor \\ Instituto de Aeronáutica e Espaço - IAE \\ São José dos Campos/SP - Brasil \\ izidororir@iae.cta.br \\ Wilson Kiyoshi Shimote, Mestre \\ Instituto de Aeronáutica e Espaço - IAE \\ São José dos Campos/SP - Brasil \\ wilsonwks@iae.cta.br \\ Luiz Cláudio Pardini, Doutor \\ Instituto de Aeronáutica e Espaço - IAE \\ São José dos Campos/SP - Brasil \\ pardinilcp@iae.cta.br
}

\section{RESUMO}

O presente trabalho mostra estudo conduzido no Instituto de Aeronáutica e Espaço, organização do Departamento de Ciência e Tecnologia Aeroespacial (DCTA/IAE), para investigar o consumo da proteção térmica, inserto na garganta da tubeira e borracha EPDM da parte convergente da tubeira, durante ensaio de queima estática do motor-foguete. Durante este estudo foram realizados ensaios que visavam à avaliação do desempenho da ablação do material do inserto da garganta da tubeira e também da formulação de borracha para proteção térmica do envelope-motor e do sistema convergente, além de verificarem a funcionalidade da adesão entre o propelente e a borracha. Especificamente para o trabalho aqui apresentado, serão analisados apenas resultados inerentes à avaliação do inserto da tubeira e deterioração da borracha EPDM na interface com o inserto de grafite para um tempo de ensaio de $56 \mathrm{~s}$. Foi verificada, após ensaios, a presença de não conformidades em componentes do motor, que, posteriormente, levaram a uma análise criteriosa de suas causas e a implementação de soluções para reprojeto de componentes visando, assim, aumentar a segurança e garantir a integridade estrutural do motorfoguete para continuidade dos ensaios.

Palavras-chave: VLM-1. Ensaio de queima. Motor-teste cigarro. Inserto de grafite.

Recebido / Received / Recibido $02 / 03 / 16$
Aceito / Accepted / Aceptado

$13 / 06 / 16$ 


\begin{abstract}
This work presents the study conducted at the Institute of Space and Aeronautics, an organization of the Department of Science and Aerospace Technology (DCTA-IAE, in the Portuguese acronym), to investigate the erosion of the thermal protection, nozzle throat insert, and thermal protection of the convergent manufactured in EPDM rubber of the convergent section of the nozzle, during the sub scale solid propellant rocket motor static firing test. During this study, tests were conducted in order to evaluate the performance of the nozzle ablation of insert material and also of the rubber to protect thermally the metallic motor case and also to the convergent, in addition to verifying the functionality of the adhesion between the propellant and the rubber. For the work herein presented, specifically, only the results inherent to the evaluation of the nozzle insert material and the deterioration of the EDPM rubber in the interface with the conducted in order to evaluate the performance of nozzle ablation of insert material, and also of the rubber to protect thermally the metallic motor case and also to the convergent, in addition to verifying the functionality of the adhesion between the propellant and the rubber. For the work herein presented, specifically, only the results inherent to the evaluation of the nozzle insert material and the degradation of the EDPM rubber in the interface with the graphite material insert for a test time of $56 \mathrm{~s}$ will be analyzed. After the tests, non-conformities were detected in components of the engine that subsequently led to a careful analysis of the reasons, as well as to the implementation of solutions for the redesign of components with the aim of improving the safety and assuring the structural integrity of the rocket engine for further tests.
\end{abstract}

Keywords: VLM-1. Firing test. End-burning test-engine. Graphite material insert. RESUMEN

Este trabajo presenta estudio dirigido en el Instituto de Aeronáutica y Espacio, organización del Departamento de Ciencia y Tecnología Aeroespacial (DCTA/IAE), para investigar el consumo de la protección térmica, inserto en la garganta de la boquilla y goma EPDM de la parte convergente de la boquilla, durante ensayo de quema estática del motor-cohete. Durante este estudio fueron hechos ensayos que tenían como objetivo la evaluación del desempeño de la ablación del material del inserto en la garganta de la boquilla y también de la formulación de goma para protección térmica del sobre-motor y del sistema convergente, además de verificar la funcionalidad de la adhesión entre el propelente y la goma. Específicamente para el trabajo aquí presentado, serán analizados solamente resultados inherentes a la evaluación del inserto de la boquilla y deterioración de la goma EPDM en la interface con el inserto de grafito para un tiempo de ensayo de $56 \mathrm{~s}$. Fue verificada, después de ensayos, la presencia de no conformidades en componentes del motor, que, posteriormente, llevaron a un análisis criterioso de sus causas y la implementación de soluciones para re-proyecto de componentes con la intención, así, de aumentar la seguridad y garantir la integridad estructural del motor-cohete para continuidad de los ensayos.

Palabras clave: VLM-1. Ensayo de quema. Motor-prueba cigarro. Inserto de grafito.

\section{INTRODUÇÃO}

Para os países que desenvolvem atividades espaciais a capacidade para projetar, construir e testar motores-foguetes é considerada estratégica, garantindo a eles a possibilidade de equipar seus foguetes, independentemente de influências políticas externas.

Ao longo dos anos, a experiência obtida pelo Instituto de Aeronáutica e Espaço, que é uma organização do Departamento de Ciência e Tecnologia Aeroespacial (DCTA/IAE), tem demonstrado que adquirir motoresfoguetes e seus componentes no exterior é uma tarefa extremamente delicada, pois a tecnologia de foguetes está sujeita às restrições dos países signatários do Missile Technology Control Regime (MTCR - Regime de Controle de Tecnologia de Mísseis), além de sofrer embargos de natureza política, comercial e estratégica (TORRES et al., 2009).

Para superar esses obstáculos, o DCTA/IAE vem procurando atuar de forma a desenvolver seus próprios motores e tornar-se independente de influências externas. Para atingir esse objetivo, diversos tem sido os esforços, tanto em pesquisas de novos materiais e processos quanto em ferramentas numéricas e computacionais para desenvolvimento de sistemas que integram os motores. No DCTA/IAE, a ferramenta usada especificamente para o desenvolvimento do Sistema de Proteção Térmica (SPT) do motor S50, destinado ao Veículo Lançador de Microssatélites (VLM-1), tem sido um motor em escala reduzida, denominado motor-teste, para a obtenção das características térmicas e ablativas de materiais usados em motores. Este motor tem como propósitos avaliar o comportamento do material do inserto a ser utilizado na tubeira e a formulação da borracha EPDM (Etbylene Propylene Diene Monomer) para proteção térmica tanto do envelope-motor quanto da parte convergente da tubeira.

$\mathrm{Na}$ Figura 1, é apresentada a tubeira do motor-teste, objeto deste estudo. Esquematicamente, apresentam-se a ponteira (item 01), a Tampa traseira convergente (item 02) e o inserto de material compósito (item 03). Na parte convergente da tubeira (item 02) da Figura 1, é moldada também uma proteção térmica de borracha EPDM que está suscetível à deterioração na interface com o inserto. Portanto, no presente trabalho, será apresentado um estudo para investigar o consumo da proteção térmica rígida (inserto) na parte convergente e a deterioração da borracha EPDM da tubeira na interface com o inserto observado durante a queima estática do motor por um tempo de $56 \mathrm{~s}$. 
Figura 1 - Tubeira do motor-teste. (1) Ponteira de aço; (2) Tampa traseira convergente e (3) inserto.

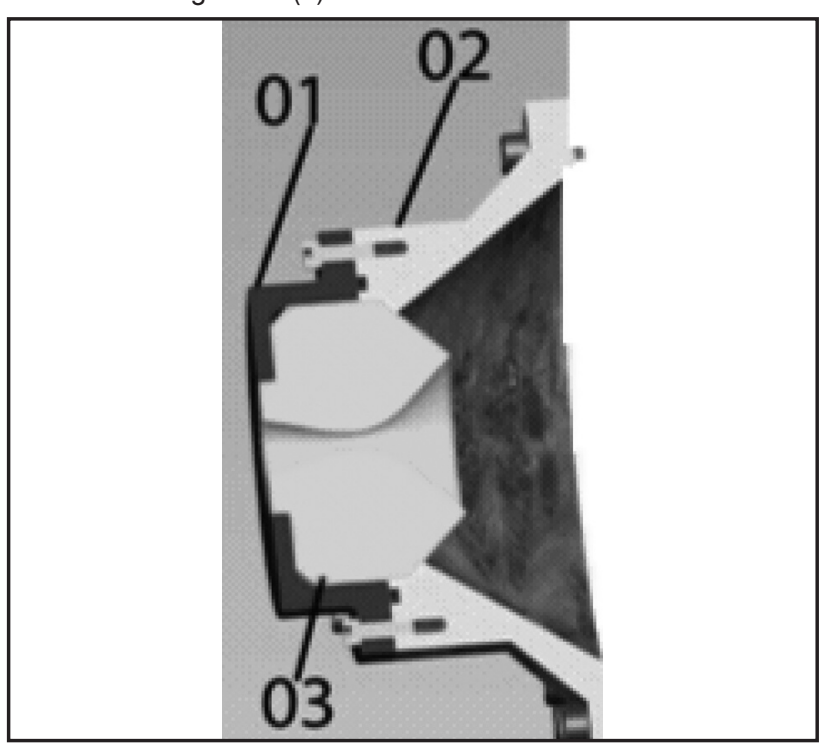

Fonte: O autor.

Essa degradação pode trazer consequências indesejáveis em relação à segurança e à integridade do motor, comprometendo a missão.

\subsection{Motor-foguete a propelente sólido}

Os motores-foguetes desenvolvidos no DCTA/ IAE possuem sistemas de propulsão química, em que a reação de combustão do propelente sólido produz energia térmica na forma de gases a elevada temperatura e alta pressão. Os gases gerados na câmara de combustão são ejetados pela tubeira onde ocorre a conversão da energia térmica em cinética, gerando empuxo para propulsão do sistema (SUTTON, 1992).

Propulsores de veículos espaciais são carregados com propelentes altamente energéticos e, preferencialmente, densos que fornecem elevado impulso específico e reduzem o volume dos tanques ou do envelope-motor. Um motor-foguete movido a propelente sólido é constituído basicamente de um envelope-motor, estruturado em material metálico ou bobinado em material compósito constituído de fibras de carbono/resina epóxi, para suportar a pressão interna, carregado com propelente e com geometria do bloco de propelente adequado para as especificações de desempenho do foguete. A tubeira, do tipo De Laval, integrada à parte traseira do motor, é constituída de uma parte convergente e outra divergente (SUTTON, 1992). É o componente responsável pela expansão e aceleração dos gases até atingir velocidades supersônicas (Mach >1) na seção de saída, transformando a entalpia do propelente em energia cinética. A pressão gerada no interior da câmara de combustão do motor pode atingir $10 \mathrm{MPa}$, resultando em força de empuxo da ordem de algumas centenas de toneladas-forças. No motorfoguete existe, entre o envelope-motor e o propelente, uma proteção térmica constituída por camadas de borracha, utilizada com a finalidade de impedir a transferência de calor dos gases à alta temperatura para a estrutura do foguete (SCIAMARELI et al., 2002).

No DCTA/IAE, utiliza-se um motor em escala reduzida denominado motor-teste, sendo uma ferramenta de ensaio para controle de qualidade tanto da velocidade de queima como da energia específica dos propelentes. Esses motores têm geometria do bloco de propelente com queima radial e geometria estrela e tempo de queima entre dois e quatro segundos, dependendo do tipo de propelente e da pressão de operação na câmara de combustão.

Para o propósito deste estudo, foi utilizado o mesmo envelope metálico do motor-teste, alterando-se a geometria do bloco propelente para queima cigarro, para obtenção de ensaios com diferentes tempos de queima necessários para avaliação dos materiais, e também o diâmetro da garganta da tubeira com o objetivo de manter a pressão na câmara do motor em $8 \mathrm{MPa}$. Nesta configuração o motor é constituído dos seguintes componentes: envelope metálico, proteções térmicas, tubeira, propelente e ignitor. A tubeira desse motor é composta de ponteira metálica, tampa traseira convergente, inserto, anéis de proteções térmicas e tampa dianteira. Para proteger o envelope metálico durante a queima, é utilizado um tubo cilíndrico em borracha EPDM. O propelente sólido é uma mistura heterogênea com consistência de borracha composta por resina de Hydroxyl Terminated Polybutadiene (HTPB - polibutadieno hidroxilado) como principal componente, perclorato de amônio como oxidante, alumínio em pó utilizado para elevar a temperatura do gás, além de componentes em menor percentual, utilizados para melhorar as propriedades mecânicas e adequar a velocidade de queima a condições desejadas.

A Figura 2 mostra o esquema simplificado do motorteste utilizado. Esse motor é composto de um envelope metálico, fabricado em aço SAE 4140, de comprimento 250 ou $500 \mathrm{~mm}$ dependendo do tempo especificado para cada ensaio, diâmetro interno de $156 \mathrm{~mm}$, espessura de parede 5 $\mathrm{mm}$, ignitor pirotécnico com pastilhas de nitrato de potássio, inserto da tubeira em grafite e envelope metálico, revestido internamente por um tubo em borracha EPDM para suportar as cargas mecânicas geradas pela pressão interna.

Para a proteção térmica do envelope metálico borracha EPDM é moldada e vulcanizada em uma matriz com 500 $\mathrm{mm}$ de comprimento e $15 \mathrm{~mm}$ de espessura em toda a sua extensão. Após vulcanização, a borracha é usinada no comprimento desejado, com diâmetro externo de 156 mm e interno de $126 \mathrm{~mm}$. Esse tubo de borracha é, então, inserido no tubo de queima metálico para carregamento do propelente. A adesão do propelente à borracha é feita com aplicação de primer antes do carregamento.

Após carregamento do propelente no tubo de borracha, o conjunto é levado para processo de cura em 
estufa à temperatura predeterminada, obedecendo a um ciclo térmico, em que o propelente adquire a consistência de um elastômero adequado para utilização.

A queima do propelente sólido produz gases, à temperatura de $3200 \mathrm{~K}$ e pressão $8 \mathrm{MPa}$, na câmara de combustão, que serão ejetados pela tubeira a velocidades $\geq 2100 \mathrm{~m} / \mathrm{s}$ para geração do empuxo.

Conforme o trabalho de Bucley

atribuem a corrida espacial impetrada durante o período da Guerra Fria a demanda por materiais para aplicações extremas, onde propriedades mecânicas deveriam atender aos requisitos de uso em temperaturas elevadas $\left(T>1000^{\circ} \mathrm{C}\right)$. (BUCLEY, 1993 apud GONÇALVES; PARDINI, 2009, p. 232).

As ligas metálicas, na forma de aços especiais, atenderiam parcialmente esse requisito, porque, a despeito da boa resistência mecânica, ou seja, limite de resistência a tração $\left(\sigma_{\mathrm{T}}>500 \mathrm{MPa}\right)$ e do módulo de elasticidade $(\mathrm{E}>100 \mathrm{GPa})$ apresentam alta massa específica, $\left(\varrho=7,8 \mathrm{~g} / \mathrm{cm}^{3}\right)$ para aços, quando em serviço, por longa duração, sujeitos a esforços por fluência. $\mathrm{O}$ alívio de massa em sistemas e estruturas de veículos espaciais, sem penalizar propriedades mecânicas, é crucial. Assim as pesquisas foram gradativamente direcionadas para a obtenção de materiais mais leves e que apresentassem resistência termomecânica condizente com as aplicações que demandassem esses requisitos.

Os ensaios de queima de motor permitem, assim, por meio de escala reduzida (Figura 2), determinar as características ablativas dos materiais do inserto (item 03, da Figura 1) em função do tempo de operação, simulando o referido tempo e a pressão na câmara de combustão do motor real, além de se avaliar a deterioração nos materiais do inserto.

Figura 2 - Ilustração em corte do motor-teste. Item 01: Ponteira de aço; Item 02: Tampa traseira convergente; Item 03: Inserto; Item 04: Envelope-motor; e Item 05: Tampa de fechamento dianteiro.

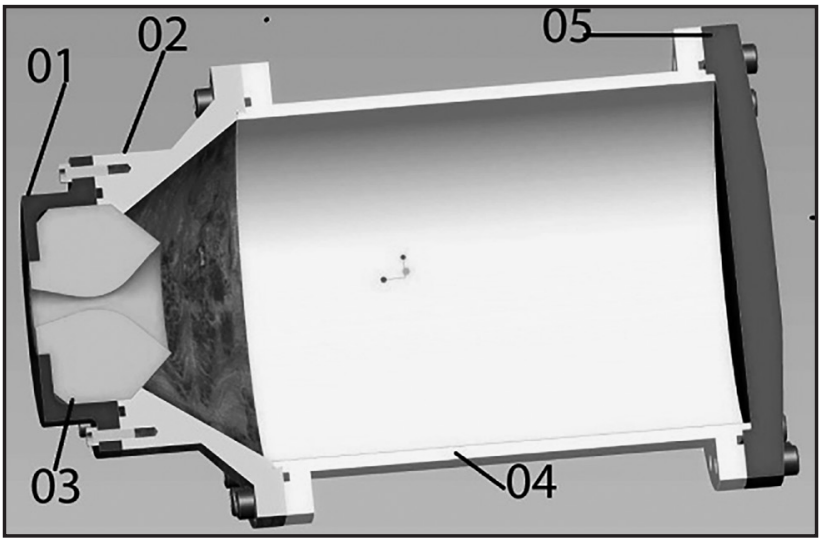

Fonte: O autor.

\subsubsection{Inserto}

O inserto mostrado na Figura 3 pode ser confeccionado a partir de materiais compósitos de Carbono Reforçado com Fibras de Carbono (CRFC), ou compósitos híbridos CRFC modificados com Carbeto de Silício (SiC), ou, no caso específico dos ensaios deste trabalho, de grafites. Esses materiais possuem como característica uma alta emissividade $(\varepsilon>0,8)$, o que proporciona um desempenho elevado na transferência da energia absorvida ao ambiente, aliviando o material metálico da ponteira metálica de permanecer a altas temperaturas durante longo tempo e aumentando, assim, a sua vida útil.

Figura 3 - Inserto de material grafite/compósito.

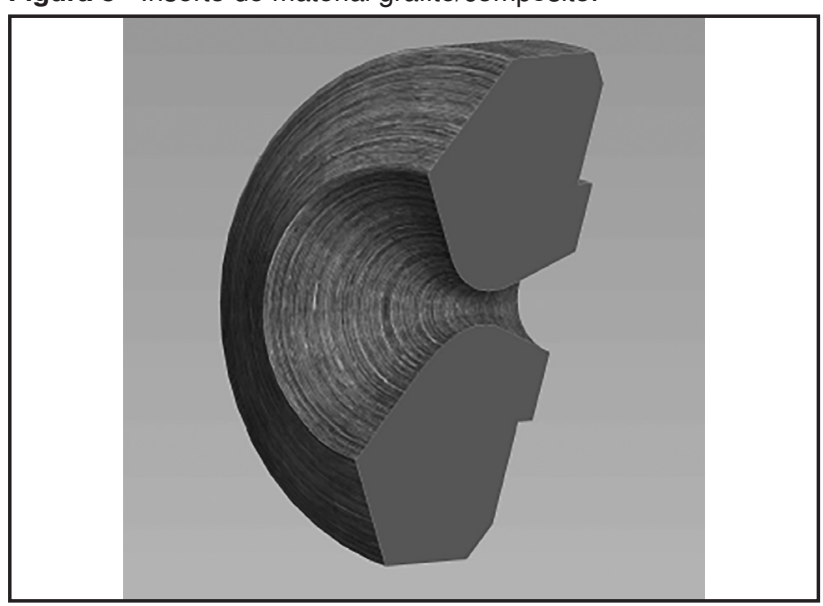

Fonte: $\mathrm{O}$ autor.

Os compósitos são materiais que consistem de duas ou mais fases distintas numa escala macroscópica, em que o desempenho mecânico e as propriedades são projetadas de modo que se obtenha um rendimento superior quando comparado às propriedades individuais de cada componente. Uma das fases, descontínua, é o reforço e tem como função principal suportar os esforços aplicados. A fase responsável pela união ou aglutinação dos reforços bem como pela transferência e distribuição de esforços é a matriz. Do ponto de vista microscópico, as interações físico-químicas entre a matriz e o reforço, denominadas interface/interfase, também são consideradas uma fase adicional (DANIEL; ISHAI, 1994).

Em particular, a indústria aeroespacial foi, em grande parte, impulsionadora do desenvolvimento dos materiais compósitos, utilizando-se das boas propriedades mecânicas, da baixa massa específica e vislumbrando a possibilidade de redução de peso frente às ligas metálicas existentes. Os primeiros passos para utilização dos compósitos na indústria aeroespacial foram iniciados em 1960, com o desenvolvimento de filamentos de boro (NATIONAL AERONAUTICS AND SPACE ADMINISTRATION, 1974). 
No setor da indústria aeroespacial, os compósitos destacam-se pela nobreza das aplicações e a engenharia aplicada para novas soluções tanto em nível de materiais como de processo, o que explica o alto valor agregado em termos de valor de mercado. Nesse tipo de indústria, os materiais compósitos desempenham um papel fundamental, principalmente nas questões relacionadas a gargantas de tubeira do sistema propulsor de um veículo lançador a propelente sólido. Nesse subsistema do propulsor, os gases que resultam desse processo apresentam altas temperaturas (acima de $2000{ }^{\circ} \mathrm{C}$ ) e são expandidos na garganta de tubeira, que tem por função propiciar o aumento da velocidade de ejeção $(\geq 2500 \mathrm{~m} / \mathrm{s}$ ), que é fator preponderante no empuxo. Esses componentes são manufaturados em materiais refratários, resistentes ao choque térmico e ao desgaste erosivo que ocorre durante a operação do veículo lançador.

O material mais utilizado na década de setenta do século XX era o grafite, que atendia, satisfatoriamente, aos requisitos de operação e dimensões. À medida que os motores foguete tiveram sua geometria aumentada, os grafites já não satisfaziam às especificações, seja pelas limitadas propriedades, seja pela limitação no tamanho da peça. Assim no final da década de setenta iniciou-se a utilização de compósitos CRFC em gargantas de tubeiras (McALLISTER; LACHMAN, 1982). O advento dos compósitos CFRC veio atender aos requisitos atuais de projeto.

A partir do objetivo inicial de qualificar uma metodologia para analisar as características ablativas do inserto fabricado em grafite, procedeu-se à avaliação dos insertos em compósito CRFC, finalizando a metodologia de qualificação.

Com a metodologia qualificada, testada e aprovada, foi iniciada a etapa de desenvolvimento de material CRFC-SiC, sob cooperação do DCTA/IAE e do Deutschen Zentrums für Luft- und Raumfahrt (DLR - Centro Aeroespacial Alemão). Caberia ao DCTA/IAE o uso do processo de infiltração líquida polimérica e ao DLR, a infiltração líquida de silício. Essas rotas de processamento são apresentadas de forma esquemática na Figura 4. O DLR e o DCTA/IAE já têm longo histórico de sucesso no desenvolvimento dos foguetes VS-30, VS-30 ORION e VSB-30. Por conseguinte as duas organizações têm relacionamento maduro, baseado em interesses comuns e na divisão de responsabilidades e custos.

Figura 4 - Diagrama esquemático simplificado das etapas de processamento de compósitos de fibra de carbono reforçados com matriz híbrida C-SiC. As temperaturas mostradas são referentes às temperaturas do processo.

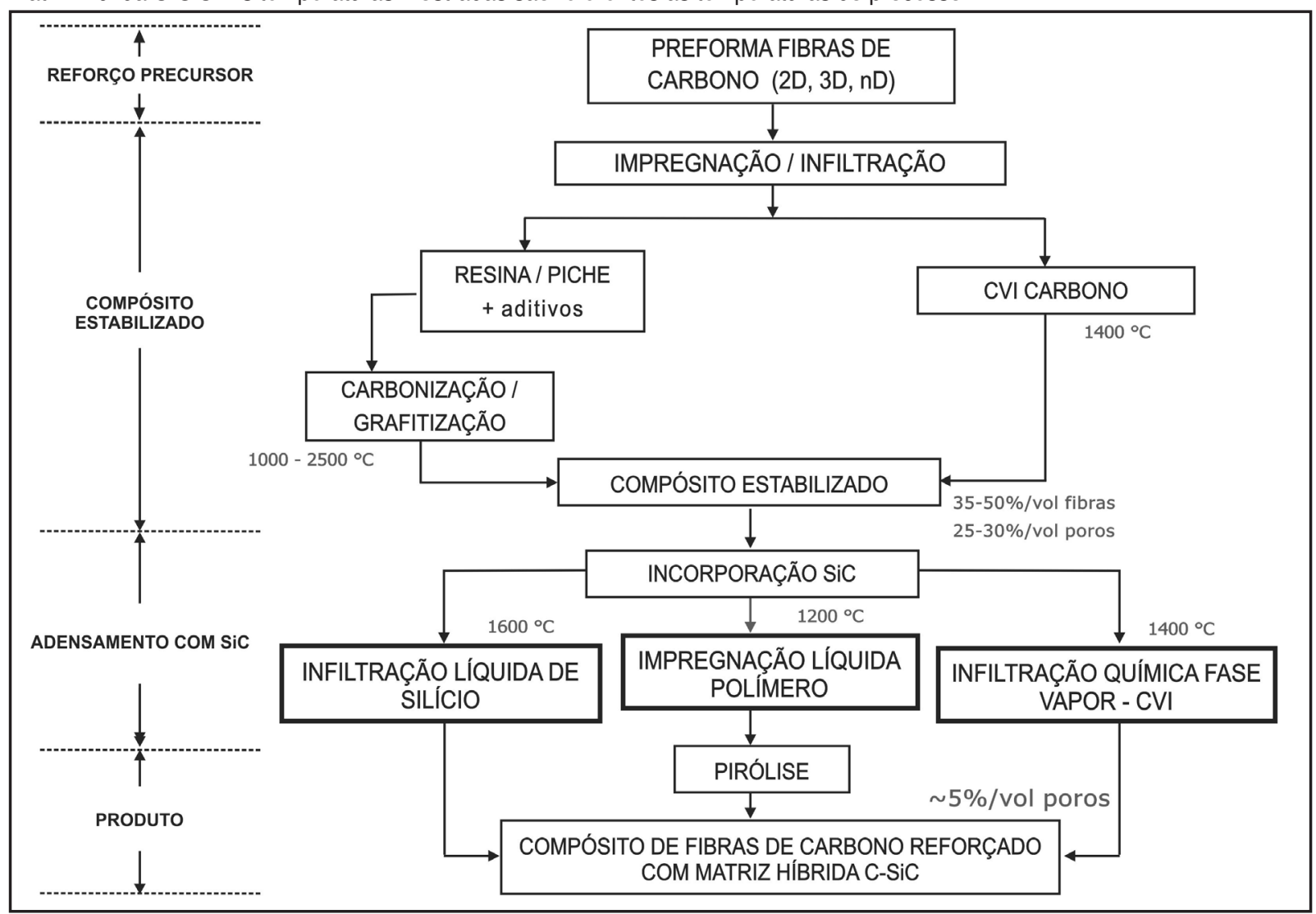

Fonte: Adaptado de Pardini e Gonçalves (2009, p. 233). 
Segundo Gonçalves (2008), as propriedades térmicas, mecânicas, ablativas e de resistência à erosão do compósito CRFC vão definir qual o tipo de reforço adequado à aplicação que se vislumbra. Portanto, para este trabalho, foi definida para o desenvolvimento do DCTA/IAE a preforma tetradirecional (4D) planar. Essas preformas apresentam massa específica que podem variar de $0,5 \mathrm{~g} / \mathrm{cm}^{3}$ a $1,0 \mathrm{~g} / \mathrm{cm}^{3}$ e cerca de 40 $50 \%$ de porosidade.

No DCTA/IAE, o início do processo de manufatura do compósito é apresentado na Figura 5 para um compósito 4D CRFC-SiC, em que a montagem da estrutura esquelética da preforma será a estrutura básica para o processo de densificação (KRATSCH,1981; MAISTRE; EITMAN, 1976). As preformas 4D são montadas, manualmente, de forma similar à montagem de um lego, resultando na forma geométrica do componente que se deseja obter. A montagem da preforma é realizada em um gabarito. Inicialmente, são dispostas as varetas perpendiculares ao plano, conforme mostra a Figura 5 (a), nas posições definidas pelo gabarito.

Como a preforma foi projetada de forma que as varetas $(\varnothing=2 \mathrm{~mm})$ se justapõem umas em relação às outras em 4 direções, a disposição das varetas no plano toma a forma da Figura 5 (b).

Figura 5 - Preforma. (a) Início da montagem da preforma 4D-plana pelo posicionamento de varetas na posição vertical, em gabarito de espuma de poliuretano. (b) Vista do posicionamento das varetas na preforma 4D-planar nas direções $0 / \pm 60^{\circ}$.

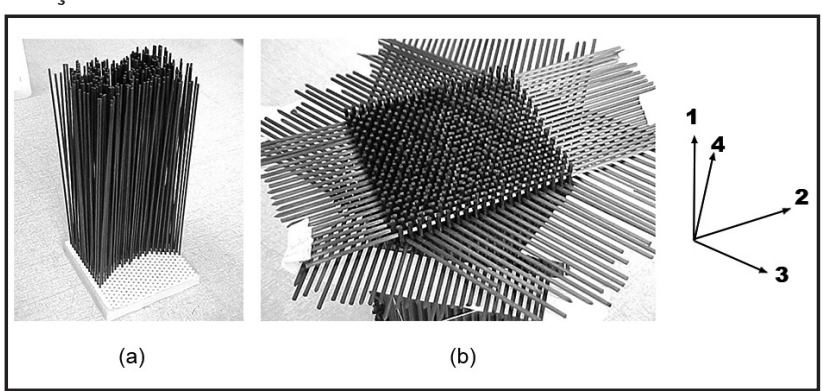

Fonte: $\mathrm{O}$ autor.

A Figura 6 mostra a sequência do processo de construção da espessura da preforma, em que as varetas são posicionadas no plano horizontal. Nessa etapa, a espessura é continuamente construída. Vale salientar que esse processo é bastante trabalhoso, pois envolve um tempo significativo de trabalho e deve ser conduzido de forma cuidadosa para que se evitem erros no posicionamento das direções predefinidas.
Figura 6 - Detalhe do posicionamento das varetas no plano da preforma 4D-planar.

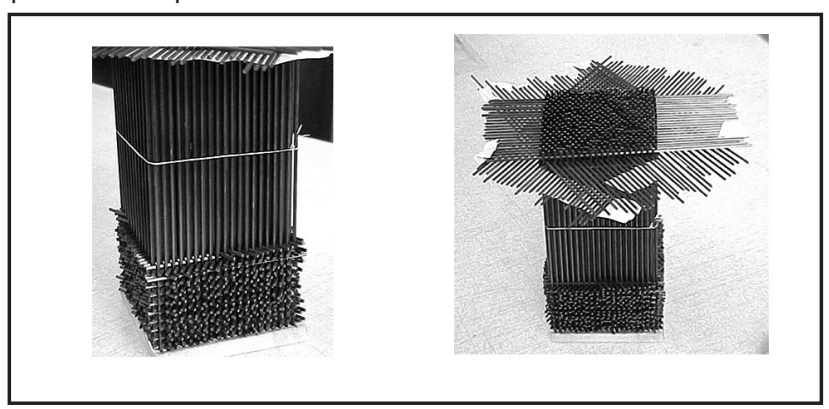

Fonte: $\mathrm{O}$ autor.

A Figura 7 mostra as fases finais da manufatura da preforma 4D planar. A disposição das varetas se completa até o topo, como mostra a Figura 7 (a) e (b). Nesse ponto, para manter as varetas em suas posições, evitando-se a movimentação, e realizar o processo de impregnação, é necessário, primeiramente, aplicar um adesivo de secagem rápida na superfície da preforma.

Figura 7 - (a) Construção da espessura. (b) Preforma concluída.

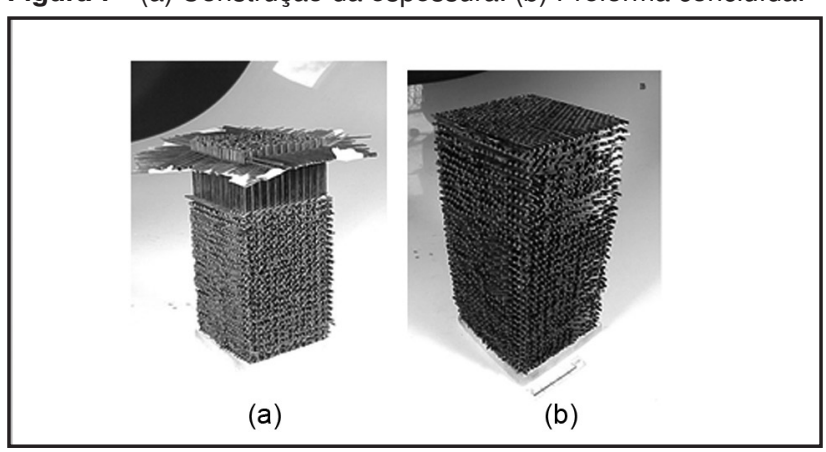

Fonte: O autor.

Para a obtenção do compósito estabilizado, como mostrado na Figura 4, a preforma montada é impregnada com resina fenólica e submetida a realização de ciclos de impregnação/carbonização subsequentes para atingir uma massa específica, que pode atingir até $1,90 \mathrm{~g} / \mathrm{cm}^{3}$, para aplicações estruturais (PARDINI; GONÇALVES, 2009).

No desenvolvimento do DCTA/IAE, o adensamento com SiC envolveria a utilização de um polímero de silicone para preenchimento de poros e microtrincas decorrentes do processo de carbonização $\left(1000^{\circ} \mathrm{C}\right)$. Ao final do processo, poros e microtrincas remanescentes devem representar cerca de 5\%/volume, que é o limite máximo aceitável para aplicações destinadas a gargantas de tubeiras e proteções térmicas de reentrada atmosférica (PARDINI; GONÇALVES, 2009). 


\section{METODOLOGIA}

No ensaio de queima em motores-testes realizados no DCTA/IAE para um tempo de $56 \mathrm{~s}$, ao se determinar as características ablativas dos materiais candidatos a inserto/garganta de tubeira para o motor do veículo lançador de microssatélites, foram observados dois problemas principais. O primeiro foi o aquecimento na parte externa da ponteira de aço, caracterizado por um aspecto oxidado do metal, conforme mostra a Figura 8.

Figura 8 - Imagem da ponteira de aço após ensaio de queima estática.

(6)

Fonte: $\mathrm{O}$ autor.

Após análise, concluiu-se que esse aquecimento foi provocado pela transferência de calor dos gases da combustão do propelente para o material do inserto da tubeira e deste para a parte metálica. Esse fato foi avaliado como crítico e decidiu-se pela utilização de uma proteção térmica, em fibras de carbono/resina fenólica, na interface entre a ponteira metálica e o inserto.

O segundo foi uma deterioração intensa da proteção térmica em EPDM na interface entre o inserto de grafite e a borracha da tampa traseira convergente, conforme mostra a Figura 9.

Figura 9 - Deterioração da borracha na tampa traseira convergente após ensaio de queima estática.

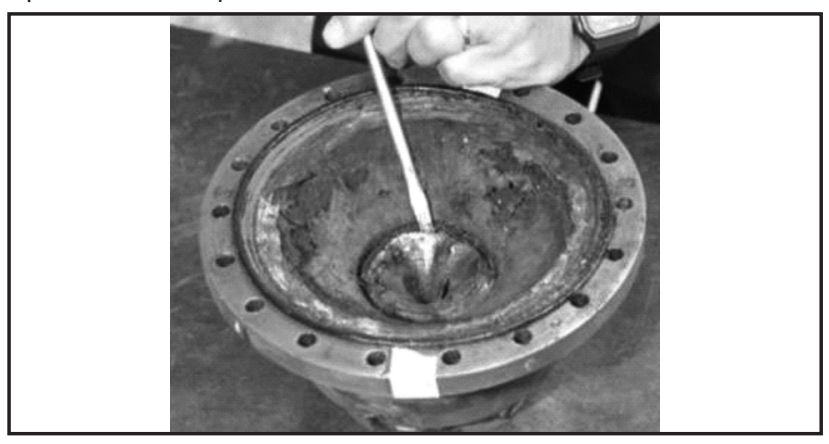

Fonte: O autor.

Após análise da borracha concluiu-se que a origem do problema observado é decorrente de um sobreaquecimento oriundo das altas temperaturas dos gases que são liberados durante a queima do motor, que, em contato com o inserto de grafite, superaquece essa região, levando a deterioração da borracha. Este aquecimento compromete a segurança do ensaio, pois pode levar ao rompimento da tampa traseira convergente pela degradação das propriedades mecânicas do aço. Decidiu-se então modificar o projeto da ponteira de aço (Figura 10) de forma a adotar uma proteção térmica rígida, fibra de carbono/resina fenólica naquela interface para reduzir a transferência de calor.

Figura 10 - llustração da Ponteira (em $1 / 2$ corte).

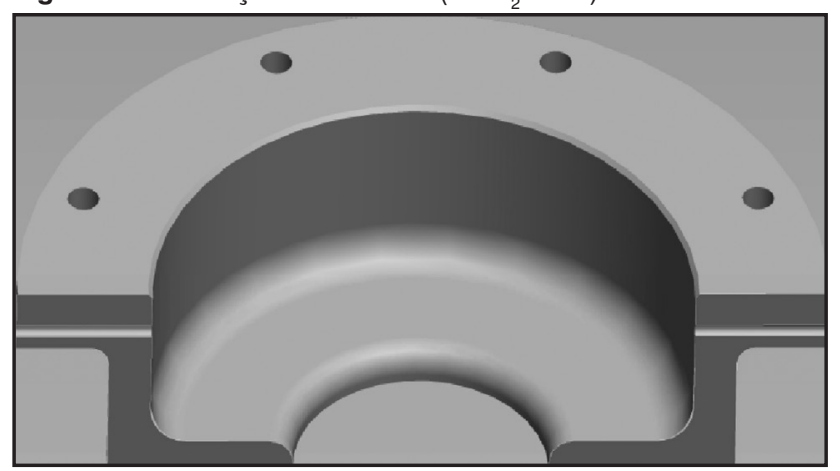

Fonte: $\mathrm{O}$ autor.

Para solucionar o problema do aquecimento, foi adotada a seguinte metodologia: adicionou-se à ponteira, nas interfaces do inserto com as partes metálicas, uma proteção térmica rígida de um compósito de fibra de carbono/resina fenólica. A ponteira modificada e a proteção térmica de fibra de carbono/resina fenólica são mostradas na Figura 11 (a) e (b).

Figura 11 - Imagem da ponteira modificada. (a) Ponteira de aço e proteção térmica. (b) Ponteira integrada à proteção térmica.

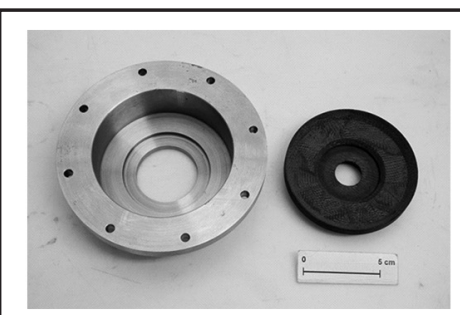

(a)

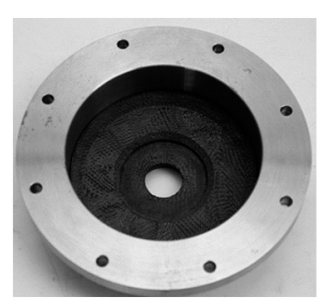

(b)
Fonte: $\mathrm{O}$ autor.

No inserto de grafite, foi realizada uma usinagem do diâmetro externo e adicionada, na interface do inserto com a parte metálica da ponteira, uma proteção térmica fabricada em compósito de fibras de carbono/resina fenólica. O conjunto inserto modificado com a proteção térmica rígida é apresentado na Figura 12. 
Figura 12 - Inserto de material de compósito/ grafite com proteção térmica.

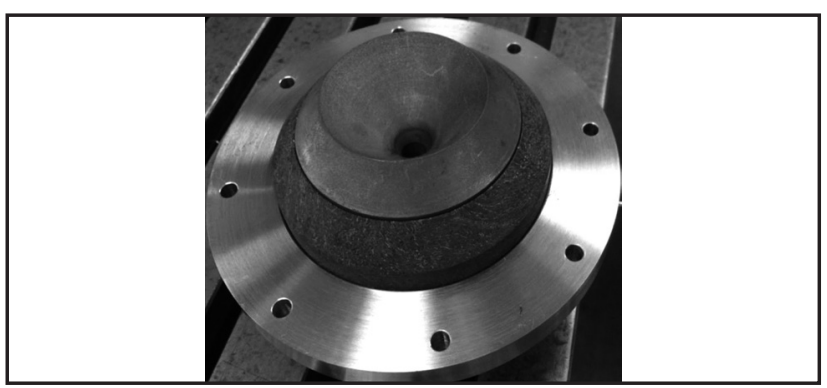

Fonte: $\mathrm{O}$ autor.

Para solucionar o segundo problema, adotou-se uma Proteção Térmica Rígida (PTR), também de compósito de fibras de carbono/resina fenólica, para a tampa traseira convergente na interface entre o inserto e a borracha, conforme mostra a Figura 13 (a) e (b).

Figura 13 - Proteção Térmica Rígida (PTR) usada. (a) Vista superior. (b) Vista lateral.

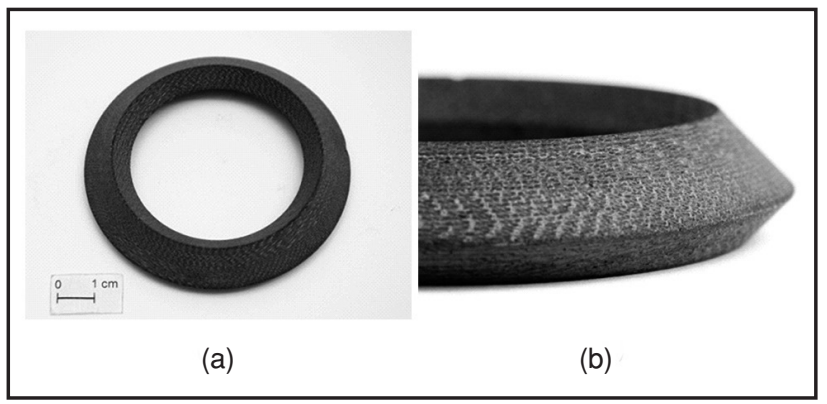

Fonte: $\mathrm{O}$ autor.

A Figura 14 mostra, esquematicamente, o motorfoguete com as modificações.

Figura 14 - llustração em corte do motor-teste com tubeira modificada. Item 01: Ponteira de aço reprojetada; Item 02: Proteção térmica da ponteira; e Item 03: Proteção térmica que envolve o inserto.

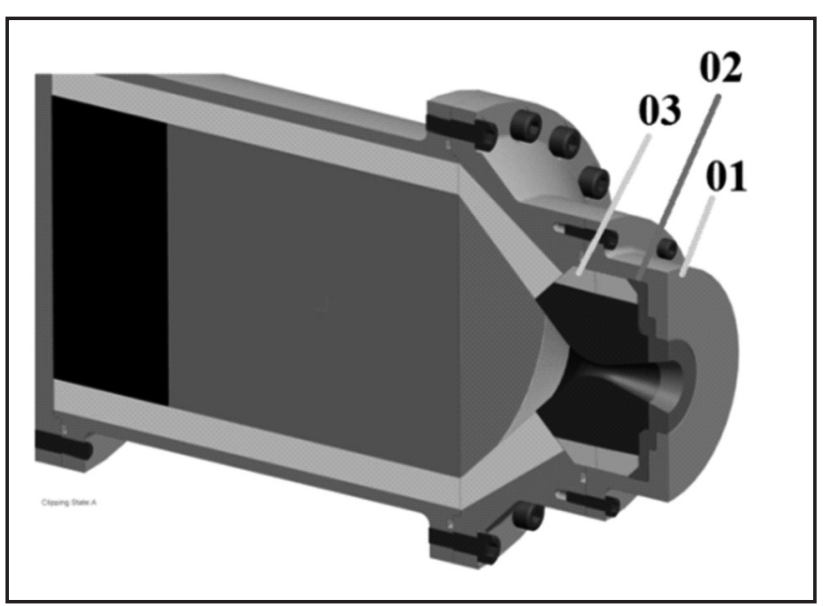

Fonte: $\mathrm{O}$ autor.

\section{RESULTADOS E DISCUSSÃO}

Os resultados dos ensaios realizados, tendo em vista a solução dos problemas citados para o tempo de ensaio de $56 \mathrm{~s}$, foram satisfatórios. As proteções térmicas, fabricadas em compósito de fibras de carbono/resina fenólica, são altamente eficazes para serem utilizadas como barreiras térmicas em sistemas em que a solicitação térmica é elevada. Como em motores-foguetes os materiais metálicos como o aço e alumínio são utilizados como elementos estruturais para suportar elevados níveis de pressão interna e a sua utilização como proteções térmicas tem se tornado essencial para preservar as suas características mecânicas. Os problemas apresentados foram solucionados adotando-se nos ensaios de queima estática de motor teste a inserção de PTR conforme apresentado nas Figuras 12 e 13.

Nesses ensaios, foram obtidas curvas de empuxo no eixo do motor em função do tempo com objetivo de se determinar a força gerada pelo motor, as características propulsivas do motor e as características balísticas do propelente. Foram realizadas medidas dimensionais para mapear o perfil interno do inserto e da seção convergente (em borracha EPDM) que reveste a tampa traseira. Especificamente para os objetivos do presente trabalho, os resultados obtidos são apresentados nas Figuras 15 e 16.

$\mathrm{Na}$ Figura 15, verifica-se que o problema apresentado na Figura 8 foi completamente solucionado com a inserção das proteções térmicas. Observa-se, nesta imagem, que, na ponteira de aço, ocorreu somente o acúmulo de fuligem, resultante da queima do propelente, e os efeitos térmicos dos gases sobre a parte metálica da tubeira foram eliminados.

Figura 15 - Motor-teste no banco de ensaio após o ensaio de queima.

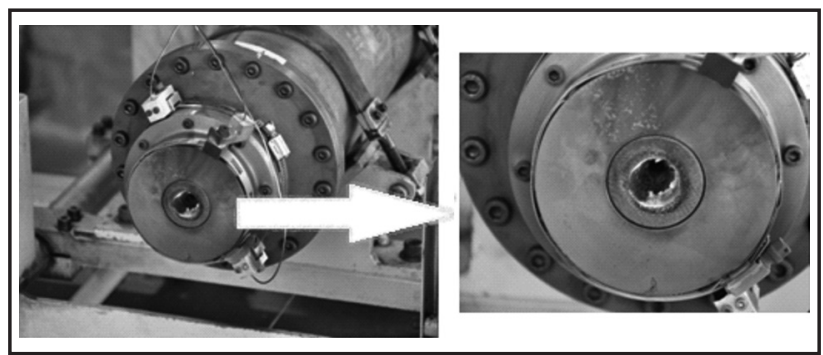

Fonte: $\mathrm{O}$ autor.

Na Figura 16, verifica-se que o problema apresentado na Figura 9 também foi completamente solucionado com a implementação da solução proposta neste trabalho. 
Observa-se, nesta imagem, que não ocorreu, após o ensaio, a deterioração da borracha EPDM na interface com o inserto de grafite.

Figura 16 - Região interna da tubeira após o ensaio de queima.

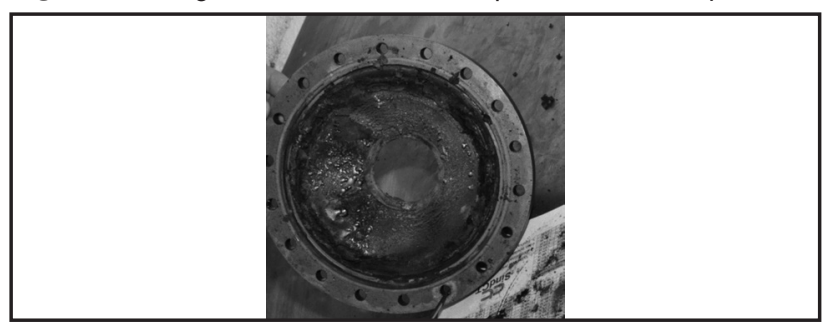

Fonte: $\mathrm{O}$ autor.

A temperatura do material do inserto, durante a operação por $56 \mathrm{~s}$ do motor, foi monitorada por termopares, conforme apresentado na Figura 17. Foram instalados três termopares em três pontos do inserto a uma profundidade $25 \mathrm{~mm}$ e a temperatura máxima observada no inserto nesses pontos foi de $1000{ }^{\circ} \mathrm{C}$.

\section{CONCLUSÕES}

Os resultados obtidos no ensaio, com a adoção das soluções de projeto para as peças da tubeira, evidenciaram redução significativa na temperatura das partes metálicas que envolvem o inserto de grafite, levando, portanto, à conclusão de que a adoção de proteções térmicas em compósito de fibra de carbono/resina fenólica entre o inserto e o metal foi eficaz como barreira térmica. Verificou-se, também, que a adoção de uma Proteção Térmica Rígida (PTR) no convergente, na interface entre a borracha e o grafite, eliminou a erosão na borracha, como mostram, respectivamente, as Figuras 15 e 16.

Os resultados evidenciaram, portanto, que, adotada a solução com proteções térmicas para um tempo de $56 \mathrm{~s}$, eliminaram-se os problemas observados e a solução deverá ser utilizada pelos pesquisadores do DCTA/IAE em todos os ensaios subsequentes neste trabalho com inserto de grafite, independentemente do tempo de queima.

\section{AGRADECIMENTOS}

Os autores agradecem ao gerente do VLM-1 Dr. Luis Eduardo Vergueiro LOURES da Costa pelo apoio financeiro, às Divisões de Química (AQI), Mecânica (AME), Materiais (AMR) e Integração e Ensaios (AIE) do Instituto de Aeronáutica e Espaço e à empresa CENIC pela cooperação e pelo apoio técnico na preparação dos componentes e na execução dos ensaios.

Figura 17 - Curva de temperatura do inserto obtida através do termopar. $\mathrm{CH}$ identifica os canais de medida e a imagem à direita, $\mathrm{O}$ posicionamento dos termopares no motor.

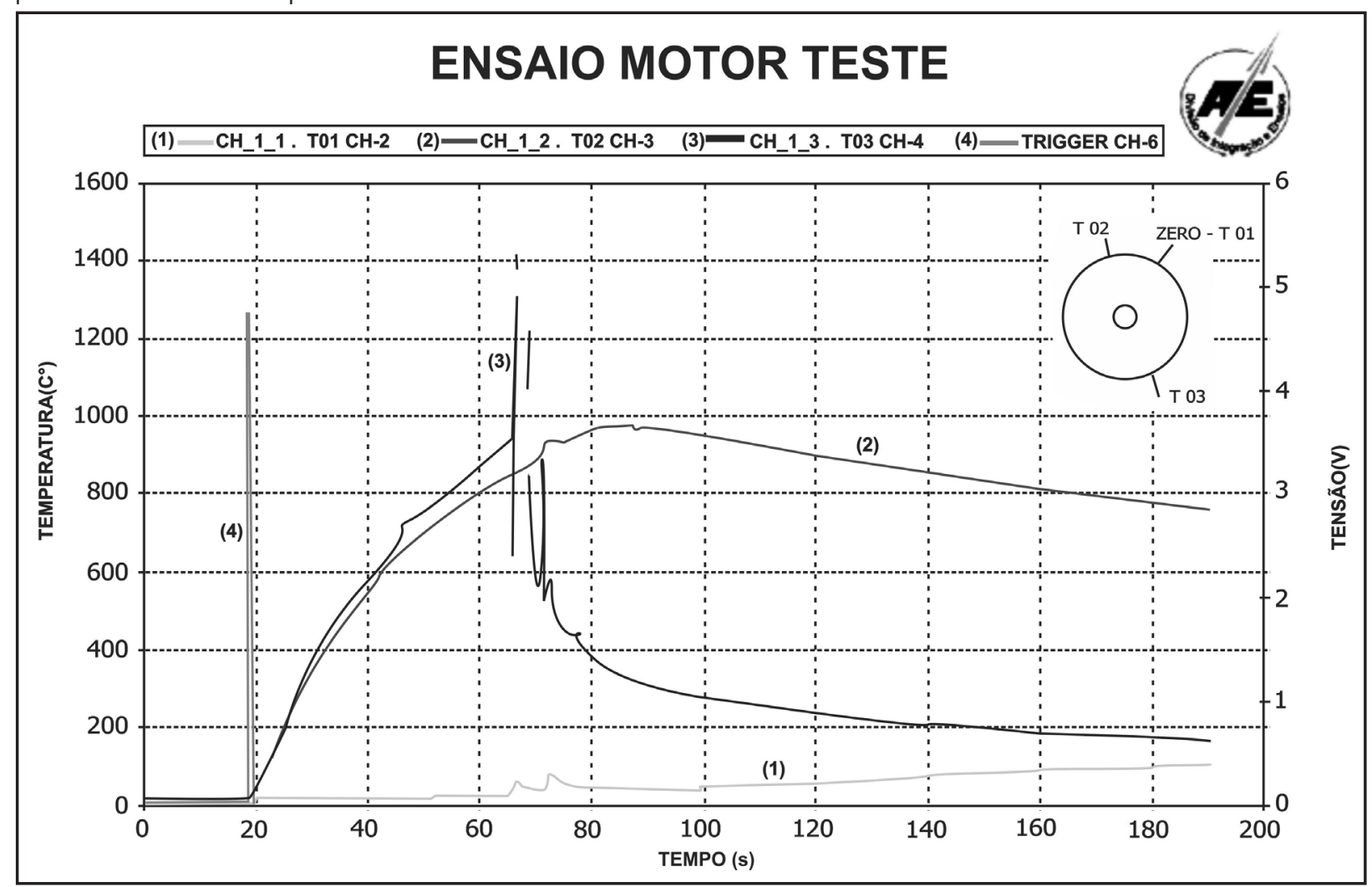

Fonte: $O$ autor. 


\section{REFERÊNCIAS}

DANIEL, I. M.; ISHAI, O. Engineering mechanics of composite materials. New York: Oxford University Press, 1994.

GONÇALVES, A. Caracterização de materiais termoestruturais a base de compósitos de carbono reforçados com fibras de carbono (CRFC) e carbonos modificados com carbeto de silício (SiC). 2008. 226 f. Tese (Doutorado)-Curso de Pós-Graduação em Engenharia Mecânica e Aeronáutica, Instituto Tecnológico de Aeronáutica, São José dos Campos, SP, 2008.

KRATSCH, K. M.; EITMAN, D. A. Method for fabricating a reinforced composite. United States patent US 4252588, 24 Feb. 1981.

MAISTRE, M. A. Development of a 4D reinforced carbon-carbon composite. American Institute of Aeronautics and Astronautics (AIAA), p. 76-607, 1976.

MCALLISTER, L. E.; LACHMAN, W. L. Multidirectional carbon-carbon composites. In: HANDBOOK of composite. New York: Elsevier Science Publishers, 1983. v. 4. p. 109-175.

NATIONAL AERONAUTICS AND SPACE ADMINISTRATION. Advanced composite materials - vehicle design criteria. 1974. Report SP8108.

PARDINI, L. C.; GONÇALVES, A. Processamento de compósitos termoestruturais de carbono reforçado com fibras de carbono. Journal of Aerospace Technology and Management, São Paulo, v. 1, n. 2, p. 231-241, July/Dec. 2009.

REIS, R. I.; SHIMOTE; W. K. Ensaios da primeira configuração de motores testes com propelente PC01 e inserto de grafite para testes de desenvolvimento da tubeira e proteções térmicas do motor S50 do veículo Lançador de Microssatélites (VLM-1). São José dos Campos - SP: Instituto de Aeronáutica e Espaço, 2014. Relatório de Ensaio (DCTA/IAE) n. 593-111200/E0001.

Ensaios da segunda configuração de motores testes para desenvolvimento de insertos de tubeira e proteções térmicas do motor S50. São José dos Campos - SP: Instituto de Aeronáutica e Espaço, 2015. Relatório de Ensaio (DCTA/IAE) n. 001/APE/2015.

SCIAMARELI, J.; TAKAHASHI, M. F. K.; TEIXEIRA, J. M. Propelente sólido compósito polibutadiênico: I- influência do agente de ligação. Química nova, v. 25, n. 1, p. 107-110, 2002.

SUTTON, G. P. Rocket propulsion elements. 8. ed. New York: Wiley, 1992.

TORRES, M. F. C. et al. Propulsão líquida no IAE: visão das atividades e perspectivas futuras. Journal of Aerospace Technology and Management, São Paulo, v. 1, n. 1, p. 99-106, jan./jun. 2009. 